\title{
LA GRAN MORAL
}

\section{MACINTYRE Y EL CARÁCTER INTEGRADOR DE LA FILOSOFÍA PERENNE}

\author{
THE GREAT MORAL
}

MacIntyre and the integrative character of the perennial philosophy

A GRANDE MORAL

MacInteyre e o caráter integrador da filosofia perene

Carlos Andrés Gómez Rodas

(Sociedad Internacional de Estudios macintyreanos) cgomezrodas@gmail.com

\author{
Arjuna Gabriel Castellanos Muñoz \\ (Institución Educativa La Milagrosa) \\ acastellanosm@hotmail.com
}

Tulio Rafael Amaya de Armas

(Facultad de Educación de la Universidad Católica de la Santísima Concepción) tamaya@ucsc.cl

Recibido: $16 / 12 / 2019$

Aprobado: 03/01/2020

\begin{abstract}
RESUMEN
En el mundo académico contemporáneo han venido tomando fuerza, desde hace varias décadas, los temas de la interdisciplinariedad y la transdisciplinariedad, como respuesta de un sector de la comunidad científica a los problemas de la especialización y a la desconexión entre las ciencias. Como todo elemento o aspecto de la realidad, este tema requiere de una debida fundamentación filosófica que se encuentra en el pensamiento clásico. En el presente artículo se intenta mostrar la relación entre la tradición de la filosofía perenne y este fundamento, atendiendo, sobre todo, a la importancia de la mirada holística del fenómeno ético y pretendiendo sustentar que el diálogo entre las ciencias sólo es posible rescatando el paradigma metafísico, legado por los griegos a la civilización occidental y defendido por MacIntyre en su libro Ethics in the Conflicts of Modernity. An Essay on Desire, Practical Reasoning, and Narrative (University of Cambridge, 2016).
\end{abstract}

Palabras clave: Alasdair MacIntyre, filosofía perenne, realismo metafísico, aristotelismo, metafísica, ética. 
For several decades in the contemporary academic world, the issues of interdisciplinarity and transdisciplinarity have been taking hold. This as a response of a sector of the scientific community to the problems of specialization and disconnection between sciences. Like any element or aspect of reality, this subject requires a proper philosophical foundation found in classical thinking. This article attempts to show the relationship between the tradition of perennial philosophy and this foundation. This is done by paying attention, above all, to the importance of the holistic view of ethical phenomena and trying to support the idea that the dialogue between the sciences is only possible by rescuing the metaphysical paradigm bequeathed by the Greeks to Western civilization and defended by MacIntyre in his book Ethics in the Conflicts of Modernity. An Essay on Desire, Practical Reasoning, and Narrative (University of Cambridge, 2016).

Keywords: Alasdair MacIntyre, perennial philosophy, metaphysical realism, aristotelianism, metaphysics, ethics.

\section{RESUMO}

Há várias décadas, vêm tomando força no mundo acadêmico temas interdisciplinares e transdisciplinares, como resposta de um setor da comunidade científica aos problemas de especialização e de desconexão entre as ciências. Como todo elemento e aspecto da realidade, esse tema requer a devida fundamentação filosófica que se encontra no pensamento clássico. Neste artigo, procura-se mostrar a relação entre a tradição da filosofia perene e essa fundamentação, atendendo acima de tudo à importância da visão holística do fenômeno ético e pretendendo sustentar que o diálogo entre as ciências somente é possível resgatando o paradigma metafísico legado pelos gregos e pela civilização ocidental e defendido por MacIntyre em seu livro Ethics in the Conflicts of Modernity. An Essay on Desire, Practical Reasoning, and Narrative (University of Cambridge, 2016).

Palavras chave: Alasdair MacIntyre, filosofia perene, realismo metafísico, aristotelismo, metafísica, ética.

\section{Introducción}

Cuando una persona no familiarizada con el discurso filosófico, ni perteneciente a los ambientes y círculos académicos propios de la Filosofía, se pregunta por el rol de los filósofos en la actualidad, no le queda muy claro en qué consiste dado que todas las ciencias de las que oye hablar y que, seguramente, ha estudiado en algún grado — que va de la información general hasta el doctorado y el posdoctorado-, tienen claramente delimitado su objeto de estudio material y formal, incluso, las ciencias humanas - que en este mundo tecnificado y hasta "tecnófilo"- siguen apareciendo como las cenicientas en muchos contextos. La filosofía, sin embargo, aparece, casi siempre, como una disciplina que habla de todo sin tener identificado cuál es ese aspecto o esa área de lo real que la ocupa.

Según Gay Bochaca (2004), un error que pone en riesgo la actividad filosófica en esta fase de la Modernidad es el cientificismo, para el cual sólo son válidas las formas de conocimiento propias de las ciencias positivas, ubicando en el área de lo meramente imaginativo, tanto el conocimiento religioso y teológico, como el saber ético y estético, postura que fue representada históricamente por el positivismo y el neopositivismo, para los que las afirmaciones de la metafísica carecían de sentido. Es a esta metafísica a la que Aristóteles llama filosofía primera o primitiva ( $\pi \rho \omega ́ \tau \eta ~ \varphi ı \lambda o \sigma o \varphi i ́ \alpha)$, pues el concepto no es, propiamente, de origen aristotélico.

Respecto a lo anterior, el filósofo de la ciencia Evandro Agazzi, en su primer libro, Temas y problemas de filosofía de la física, publicado en italiano, en 1969, ya diagnosticaba esta problemática y definía, 
en el primer capítulo, las bases de lo que se constituiría en su respuesta a este paradigma cientificista, dejando ver así, sus marcadas influencias griegas llamativas, sobre todo, por darse en un filósofo cuyos intereses han estado en el plano de las ciencias llamadas físico-matemáticas o exactas, concepto que, implícitamente, se problematiza aquí:

\begin{abstract}
En los orígenes de la civilización occidental —es decir en el seno de la cultura de la Grecia clásica- la ciencia y la filosofía constituían un solo cuerpo. Ello no significa, según algunos parecen interpretar ingenuamente, que los grandes genios de aquella edad dichosa eran capaces de dominar a la vez los dos campos, sino que una sola forma de saber, la filosofía, abarcaba también el contenido de lo que hoy llamamos ciencia, y además se reservaba en exclusiva el propio nombre de "ciencia". La física y la matemática no se consideraban formas de saber científico que se pudieran clasificar al lado de la filosofía, sino como partes de la misma. Se encontraban subordinadas jerárquicamente a las partes más nobles, es decir a la filosofía primera o metafísica (que estudia el ser en cuanto tal, desde el punto de vista más general), y eran consideradas filosofías segundas (que estudian géneros particulares del ser). Esta es cuando menos la esencia de la doctrina aristotélica que se conservó inalterable en sus fundamentos hasta el Renacimiento (Agazzi, 1978: 23).
\end{abstract}

No muy lejos de esta aproximación se encuentra Alasdair MacIntyre, quien advierte acerca del grave error moderno de entender las distintas ciencias humanas como universos aislados que no mantienen ninguna relación, lo cual no permitiría nunca la aproximación holística a la realidad, sino que se tengan exclusivamente perspectivas, no sólo diferentes y lejanas, sino incluso contradictorias. A esta forma errada de entender a las que, en el lenguaje aristotélico, son "filosofías segundas", MacIntyre (2017) opone precisamente la visión holística e integradora del Estagirita.

Partiendo de la tesis según la cual las intuiciones de MacIntyre en relación con la importancia de la ética clásica, en vistas a dilucidar y resolver los grandes problemas de la filosofía moral moderna, hunden sus raíces en una reflexión sobre el concepto mismo de filosofía (MacIntyre, 1992). En lo sucesivo de este primer momento del artículo, se desarrollará un análisis etimológico de los conceptos de filosofía ( primigenio, con base en los testimonios escritos que se conservan hasta ahora y, manteniendo a lo largo de este recorrido, una cercanía con los clásicos griegos, particularmente, con autores como Pitágoras y Heródoto para el concepto de filósofo y filosofar, y con Aristóteles, quien propiamente es el que usa la expresión "filosofía primera" en su Metafísica, base de los planteamientos éticos expuestos en sus clásicos Ética Nicomáquea, Ética Eudemia, Gran Moral y Política. Por otro lado, se intentará mostrar cómo estos conceptos originales se encuentran presentes, explícita e implícitamente en el último trabajo de MacIntyre, fuente principal del presente artículo: Ethics in the Conflicts of Modernity. An Essay on Desire, Practical Reasoning, and Narrative (University of Cambridge, 2016) que aquí se aborda en su traducción castellana Ética en los conflictos de la Modernidad. Sobre el deseo, el razonamiento práctico y la narrativa (RIALP, 2017).

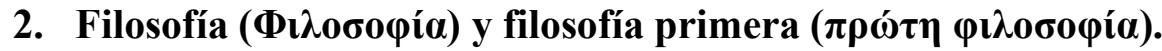

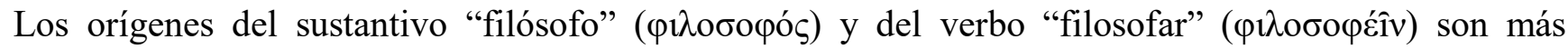

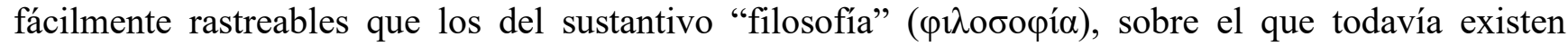
discusiones entre filólogos, historiadores y, obviamente, filósofos. La primera de las palabras mencionadas, referida al hombre o al conjunto de hombres que desean contemplar y conocer la realidad sin buscar con ello ninguna utilidad material se encuentra, según el testimonio de Cicerón, en Pitágoras, quien al ser preguntado por León cuál era su arte, "respondió que no conocía ningún arte en particular, sino que él era un filósofo" (Cicerón, 2005).

En cuanto al verbo "filosofar", que algunos traducen por "deseo de saber o conocer" ( $\varphi \imath \lambda \circ \sigma o \varphi \varepsilon ́ \omega v)$, es posible identificar su origen en los Libros de la Historia de Heródoto, en donde se dice que Creso, rey de Lidia, elogió a Solón — su huésped- diciéndole: "ya que por tu anhelo de conocimientos y de ver mundo has visitado muchos países; por ello me ha asaltado ahora el deseo de preguntarte si ya has visto al hombre más dichoso del mundo". (Heródoto, 1992). 
No obstante, las divergencias que puedan existir todavía acerca de los orígenes y el primer testimonio escrito de la palabra filosofía, el presente trabajo se suscribe a la opinión de Cordero (2009), quien afirma:

\begin{abstract}
Respecto del término "filosofía", el pasaje más antiguo que lo atestigua es bastante tardío. Se trata de un texto anónimo titulado Tratado de medicina antigua (¡ya antigua!), escrito hacia 440 a.C., pero el contexto en el cual la palabra aparece sugiere que ya formaba parte del acervo cultural de la época. Seguramente debió figurar en textos anteriores, hoy perdidos. En ese tratado (cap. XX) se dice que "hoy" la medicina "moderna" se orienta hacia la filosofia, porque un médico debe ser capaz de responder también la cuestión “¿qué es el hombre?”, que va más allá del ámbito de la medicina. Y se supone que tanto el autor del tratado como sus lectores sabían ya qué quería decir entonces "filosofía"; no lo estaban aprendiendo recién en 440 (p. 35).
\end{abstract}

La referencia de Cordero permite conectar el sentido del concepto de Filosofía en términos generales —que según su análisis formaba parte del acervo cultural de la época- con la noción aristotélica de filosofía primera ( $\pi \rho \omega ́ \tau \eta ~ \varphi \imath \lambda o \sigma o \varphi i ́ \alpha)$, pues según el Tratado de medicina antigua, el profesional o -en un lenguaje más moderno-, científico, que se encarga de preservar y recuperar la salud del cuerpo humano cuando se ha perdido, se encuentra, en su quehacer particular, con preguntas que exceden a su ciencia específica y lo llevan a la contemplación de una realidad mayor que la del cuerpo, a saberse, la naturaleza humana, o sea, el hombre en todo lo que su ser contiene, y no sólo su dimensión corporal o física. He ahí la orientación filosófica de la medicina que el texto en mención describe. Por otro lado, la misma tendencia natural de esa orientación o tendencia filosófica avanza allende las fronteras de esa pregunta por el hombre, encumbrándose hacia la cuestión misma del ser ( $\tau$ o ov), esto es hacia la pregunta fundamental del entendimiento humano por la causa de que todo lo que existe sea, pregunta cuyo sentido Alfred North Whitehead intentó expresar en lengua inglesa con las palabras “what is it all about?" (1937:178), o sea, ¿qué hay sobre todo esto?”.

Es precisamente este sentido que Aristóteles da a la metafísica, o filosofía primera, como ciencia de lo que es en tanto que algo que es, que no es diferente de la ontología, como una distinción más bien moderna ha querido señalar, ocasionando una gravísima confusión que hasta hoy acompaña a muchos estudiosos de la filosofía. En el Libro IV de la Metafísica, el Estagirita afirma:

\begin{abstract}
Hay una ciencia que estudia lo que es, en cuanto que algo que es, y los atributos que, por sí mismo le pertenecen. Esta ciencia, por lo demás, no se identifica con ninguna de las denominadas particulares. Ninguna de las otras $<$ ciencias $>$, en efecto, se ocupa universalmente de lo que es en tanto que algo que es, sino que tras seccionar de ello una parte, estudia los accidentes de ésta: así, por ejemplo, las ciencias matemáticas. Y puesto que buscamos los principios y las causas supremas, es evidente que éstas han de serlo necesariamente de alguna naturaleza por sí misma. Y, ciertamente, si también buscaban estos principios quienes buscaban los elementos de las cosas que son, también los elementos tenían que ser necesariamente elementos de lo que es, no accidentalmente, sino en tanto que algo que es. De ahí que también nosotros hayamos de alcanzar las causas primeras de lo que es, en tanto que algo que es. (Aristóteles, 1994: 23-30)
\end{abstract}

Así pues, según el planteamiento aristotélico, existe una ciencia de lo que es en tanto que algo que es, cuya importancia y dignidad es superior a las ciencias particulares, pero, además, cuya existencia resulta de primerísima importancia a la hora de fundamentar el estudio de esas mismas ciencias, pues

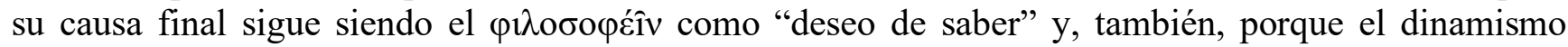

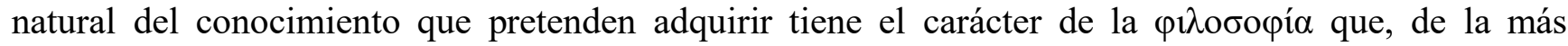
mínima partícula de la materia, recorre por la vía de las causas un camino que conduce al

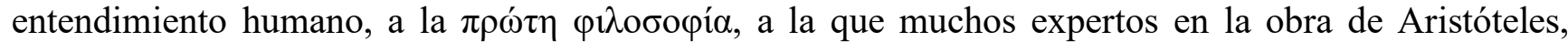

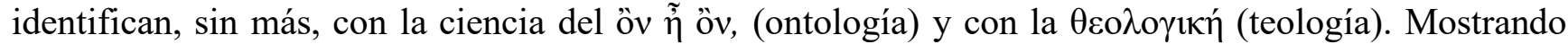
las raíces aristotélicas de su pensamiento, Santo Tomás de Aquino ofreció una síntesis magistral de esta idea cuando sentenció, en la Suma de Teología: "Es preciso que todo lo sometido a cambio y posibilidad sea reducido a algún primer principio inmutable y absolutamente necesario" (De Aquino, 2001).

En Ética en los conflictos de la Modernidad (en adelante, ECM), MacIntyre distingue la moral de la "Moral", sugiriendo que, mientras aquella reúne todas las tradiciones morales existentes que pasan por 
el lente evaluador de la ética o filosofía moral —encargada de juzgar los cánones morales existentes con base en la razón práctica y en criterios metaéticos-, la "Moral” es, más precisamente:

\begin{abstract}
...el peculiar sistema moral que es característico de la primera y la más tardía Modernidad capitalista. La Moral, que ha prosperado y todavía prospera en Europa Central y Occidental, en Norteamérica, y en otras partes de la Tierra que los habitantes de las anteriores han colonizado desde los primeros años del siglo dieciocho hasta el veinte (pp. 113-114).
\end{abstract}

Lo más interesante de esta distinción, entre todos los aspectos sugerentes que contiene, es que la Moral pareciera ser un totus que, no sólo reemplaza a la moral en el sentido que ya se explicó, sino también a la filosofía misma, de acuerdo al concepto clásico que se desarrolló líneas arriba. Esto queda mucho más claro cuando MacIntyre explica que la primera característica destacada de la Moral radica en que "es presentada por sus partidarios como una doctrina secular y un modo práctico que no permite recurrir a algo que esté más allá de ella, apelando a mandamientos reales o supuestos de procedencia divina" (2017: 114) y este último aspecto es, precisamente, lo más contrario al espíritu verdaderamente filosófico, que busca cimentarlo todo en la realidad y no en los sentimientos, la conciencia, los valores, los ideales o los modelos arbitrariamente propuestos (Pieper, 1974). Lejos de ser la Moral un sistema cimentado en ideas filosóficas pareciera ser, más bien, una ideología que censura a la fílosofía misma y le impide realizarse y desplegarse según su naturaleza, no sólo porque niega la existencia del primer principio inmutable y absolutamente necesario del que hablaba Santo Tomás en la cita antes referida, sino, además, porque amenaza al filósofo con castigarlo si cede a su esencial deseo de teorizar y saber cómo son y están realmente las cosas, pues eso podría contrariar la particular visión de la Moral y los intereses de quienes la detentan.

Si se vuelve a enfocar la atención en el concepto de filósofo como hombre o conjunto de hombres que desean contemplar y conocer la realidad sin buscar con ello ninguna utilidad material, la oposición de la Moral a este carácter se hace muchísimo más evidente porque, en dicho sistema de cosas, la utilidad material de algunas élites se pone por encima de la contemplación, el conocimiento y el bien, reeditándose así la sofística, que Sócrates con la mayéutica y, luego Platón con la Academia, intentaron superar mediante el ejercicio serio y riguroso de la Filosofía hasta el punto de sacrificar cualquier otro interés, lo cual les hace modelos del genuino filósofo, sobre todo al primero de ellos, quien dio su propia vida por negarse a someter las conquistas de su razón al poder del Estado o a los mezquinos e utilitarios fines de un despreciable contubernio entre oligarcas y demagogos.

\title{
Al describir la tercera gran característica de la Moral, MacIntyre (2017) señala:
}

\begin{abstract}
Merece la pena recalcar que en el periodo en el que la Moral se convierte en la moral dominante, los conceptos de egoísmo y altruismo pasan a ocupar un lugar más nuclear en los debates de los filósofos morales, y que después de eso, cuando los biólogos del siglo veinte que identifican la moral con la Moral tratan de explicar el surgimiento de la moral en términos evolutivos, identifican el problema de explicar el surgimiento de la moral con el de explicar el surgimiento del altruismo. Se trata de un supuesto de los profesionales de la Moral: que actuar por el bien de otros como dicta la Moral a menudo se traducirá en actuar en contra de los propios intereses y deseos (p. 114).
\end{abstract}

La oposición aquí implícita entre el bien individual y el bien público tiene como base el mismo abandono del carácter filosófico de la ética, que permite encontrar la íntima conexión entre la virtud personal y la virtud política, entre la excelencia moral de la persona concreta y el recto desarrollo de los asuntos cívicos, como bien ha señalado el filósofo español Alejandro Llano Cifuentes - a quien podría considerarse uno de los mayores representante del neoaristotelismo en el mundo de habla hispana- al exponer su célebre propuesta del "humanismo cívico" (2015). Contrario a perspectivas que plantean falsas dicotomías debido a su mirada antimetafísica de la realidad, Aristóteles es sumamente preciso a la hora de presentar la relación entre ética y política como un continuum en la Ética Nicomáquea.

Las que hoy se llaman en las universidades, y en los diversos espacios culturales, Ciencias Políticas, Jurisprudencia o Derecho, Antropología, Sociología, Arte etc. no son más que ramas de la filosofía desarrolladas, si se atiende a la tradición, a saberse respectivamente, filosofía política, filosofía del 
derecho o iusfilosofía, antropología filosófica — también esta se ocupa de la dimensión social del hombre, estudio que se distingue de la moderna sociología, cuyos orígenes se remontan al positivismo con una fortísima carga ideológica, relativista e inmanentista- y filosofía del arte o, por lo menos, no pueden estudiarse bien si no se atiende a los fundamentos que les proporciona la filosofía cuando se enfoca en esos aspectos particulares de lo real. El desprecio contemporáneo por la filosofía es simple y llanamente una consecuencia de su reducción a una disciplina más, que no es base para cualquier conocimiento, esto se debe precisamente a la renuncia de una inmensa porción de la filosofía académica a la metafísica, o filosofía primera que, permitiendo descubrir las profundas raíces de cualquier saber atinente a las filosofías segundas, les muestra su íntima conexión, camino por el cual se abren a la dimensión estrictamente teológica e, incluso, a la teología dogmática o sobrenatural (MacIntyre, 2012).

Al cerrar este primer apartado se quiere enfatizar en la importancia de comprender las etimologías y los usos originales de los conceptos de filosofía, filósofo y filosofar en vistas a la comprensión real de la tarea filosófica y del absurdo que puede implicar hablar - como tanto se hace hoy entre los "expertos"- de filosofía sin metafísica, incluso, de una ciencia sin filosofía, como si fuese posible separar tajantemente el afán científico de su carácter filosófico y el método mismo de las ciencias de sus presupuestos en la filosofía primera, cuando es claro que para el hombre griego, ni siquiera estaba tematizada su diferencia como universos separados (Agazzi, 1978), sino que más bien, se consideraba a las que hoy se llaman ciencias como filosofías segundas, jerárquicamente inferiores a la filosofía primera, ciencia de lo que es en cuanto que algo que es. Este asunto resulta de obligada comprensión para abordar la obra de MacIntyre, pero de modo especial, su último gran trabajo escrito del que el presente ensayo se ocupa, y en el que la mirada metafísica - y por tanto holística - del Estagirita se encuentra como cimiento inherente a todo el planteamiento macintyreano acerca de la ética en los conflictos de la Modernidad.

\section{La pérdida de la concepción metafísica del mundo.}

Con base en las conquistas de la filosofía griega, la ciencia medieval logró avanzar hasta construir todo un sistema de conocimientos conectados entre sí y regidos por la teología como conocimiento supremo, unificador e integrador que concluía en lo universal después de estudiar las particularidades y accidentes de todo lo que es, desde las ciencias naturales hasta las que, hoy en día, son llamadas Ciencias Sociales, pero que en ese entonces se llamaban ciencias profanas. En segundo lugar, después de la teología, venía la filosofía primera. El programa de formación de la universidad medieval expresa con claridad esta concepción cimentada en una cosmovisión en la que se vinculan armónicamente la metafísica griega y la revelación cristiana. Es más, el mismo nombre de universitas manifiesta la misma idea de generalidad o universalidad, pues en ella se enseña el universo de todas las ciencias, ascendiendo de lo particular a lo general hasta encontrar las causas primeras de todo lo que es y, así, comprender mejor su naturaleza:

\footnotetext{
El currículo de un estudiante medieval comenzaba con un ciclo de formación común para todos ellos llamado: "artes liberales", que estaba conformado por dos etapas sucesivas: el trivium y el quatrivium. En el trivium se enseñaban las artes del pensamiento y la comunicación: lógica, retórica y dialéctica. En el quatrivium se enseñaban las artes de la armonía del universo: aritmética, geometría, música y astronomía.

Una vez que el estudiante había cursado estas asignaturas, se consideraba que estaba a la altura de la cultura de su tiempo y podía iniciar una especialización. Existían tres especializaciones posibles: la medicina para la salud del cuerpo, la teología para la salud del alma y el derecho para la salud del Estado (Buitrago, 2017: 200).
}

Sin embargo con la crisis de la Primera Escolástica y la llegada del nominalismo, a comienzos del siglo XIV este paradigma clásico del conocimiento científico, sustentado en la aceptación axiomática de la capacidad humana de abstraer la naturaleza de todo aquello que es, se fue resquebrajando hasta casi desaparecer, siendo reemplazado por una visión del mundo y de las ciencias que inspiró toda la filosofía moderna que de ellas se ha ocupado. 
Un punto de ruptura importante es el Renacimiento, cuando con el despertar de un interés muy patente por la naturaleza, "autores como el Cusano, Telesio, Bruno y Campanella proponen filosofías capaces de interpretar la naturaleza 'de acuerdo con los principios de la misma' sin recurrir a principios universales de metafísica" (Agazzi, 1978: 28). Luego de comentar la importancia que tuvo el descubrimiento de la configuración real de la Tierra en el menoscabo de la ciencia aristotélica y la cosmovisión que de ella provenía.

La concepción de una mente racional ordenadora, que la Escolástica identificó con el entendimiento divino, también entró en crisis con el pensamiento de Giordano Bruno, pues mientras los escolásticos y, fundamentalmente Santo Tomás de Aquino, habían conectado las vías aristotélicas para llegar a la causa primera con la teología católica - afirmando la posibilidad de conocer al creador cuya ley eterna dirigía todo lo existente-, Bruno admitía que hay una "mente sobre las cosas", de la que deriva todo lo demás, pero que permanece desconocida para el entendimiento humano. Todo el universo es efecto de este primer principio, pero no se puede remontar al conocimiento de la causa partiendo del conocimiento de los efectos, así como no se puede llegar al conocimiento del escultor por el conocimiento de la estatua que ha esculpido. Este principio no es otro que el Uno de Plotino revisado por un renacentista.

Así como en Plotino (1998) el entendimiento deriva del supremo Principio, Bruno (2018) habla de un Entendimiento universal, pero lo entiende de modo marcadamente inmanentista, como mente de las cosas o, precisamente, como facultad del alma universal de donde surgen todas las formas inmanentes a la materia y que constituyen con ella un todo invisible. Las formas son la estructura dinámica de la materia "que van y vienen, cesan y se renuevan", justamente porque todo está animado, todo está vivo. El alma del mundo está presente en cada cosa, y en el alma está presente el entendimiento universal, fuente perenne de formas que se renuevan continuamente.

No obstante la importancia de Bruno y muchos otros, el nombre que sobresale en esta revolución sigue siendo el de Galileo, cuyo planteamiento central no es el perfeccionamiento del método experimental hasta sus más altos niveles, ni el recurso a un componente matemático para alcanzar una metodología científica más efectiva, sino más bien, una nueva idea de la ciencia en la que se dejaba de lado la indagación por la naturaleza de las cosas, que había sido el acicate esencial de toda búsqueda filosófica desde sus orígenes en el pensamiento griego. El mayor ejemplo de esta indagación y de este empeño fue Sócrates, específicamente en lo que se refiere a su desinterés por los entes naturales en cuanto no

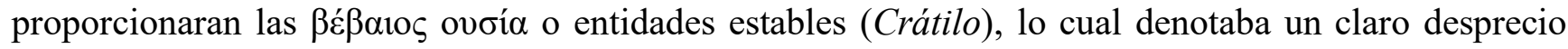
por lo particular y un deseo marcado de encontrar lo general, esto es, de dar, en palabras de Aristóteles, con "los primeros principios y las causas" (1994).

Tal vez, en la perspectiva general de la comunidad científica de entonces, la postura de Galileo pudo entenderse sencillamente como un simple desplazamiento del proyecto de conocer la verdad de la naturaleza al simple dominio utilitario de sus leyes. Agazzi (1978) logra ver los alcances reales de esta nueva y revolucionaria forma de entender las ciencias y su método:

\footnotetext{
No transcurrió mucho tiempo hasta que se vio claramente que en realidad había nacido un nuevo enfoque en la investigación científica de la naturaleza, y este enfoque ha sido posteriormente característico de la ciencia moderna, por oposición al empleado por la ciencia en el sentido clásico o filosofía (p. 29).
}

El nuevo paradigma científico que comienza con Galileo explica el sistema filosófico cartesiano y el mecanicismo que le es inherente, así como las bases del pensamiento kantiano, para el cual el modelo de cientificidad no venía ya dado por la filosofía primera, sino más bien, por la matemática y la física. En este sentido el filósofo alemán afirma, en un desprecio categórico por la metafísica clásica: "Únicamente de esta forma ha alcanzado la ciencia natural el camino seguro de la ciencia, después de tantos años de no haber sido más que un mero andar a tientas" (Kant, 2006).

Este es en buena medida el contexto que da base a la nueva situación en que queda la tradición aristotélico-tomista, y que MacIntyre complementa en el capítulo IV de ECM cuando intenta ofrecer 
claves para los actuales debates en clave tomista. Si bien el filósofo escocés resalta las posibilidades del tomismo en la actualidad, no ignora las complicaciones de una situación en que la concepción metafísica del mundo ha sido reemplazada por el discurso racionalista moderno, que deconstruye —cuando no destruye — toda la tradición perenne del realismo aristotélico:

Lo que Tomás de Aquino aporta es un replanteamiento radical del aristotelismo, con una versión que, siendo teísta, acercó de un modo distinto el original aristotélico a sus contemporáneos. Tras él la labor de elucidación y crítica continuó a lo largo de periodos en los que el tomismo ha tenido que afrontar objeciones y problemas planteados sucesivamente por la nueva comprensión de la ley y la moral que encuentra expresión en la creación del Estado moderno, por la nueva ciencia natural anti-aristotélica, por la Ilustración, y por la filosofía post-kantiana. Lo que tenemos ahora es, según aduce el aristotelismo tomista, la mejor exposición de la teoría hasta la fecha, juzgada en virtud de los mejores criterios de verdad y justificación racional con los que hemos dado, una exposición protagonizada por una serie de autores que han sido capaces de dar adecuada réplica a las principales objeciones que se han presentado en contra (p. 197).

Podría llamarse "autonomismo" a este proceso de emancipación de las ciencias, o sea, a su desvinculación del saber filosófico que, de acuerdo con una metafísica realista, tiene superioridad jerárquica y primacía sobre ellas. Como consecuencia de esta concepción autonomista en la que las ciencias, llamadas antes filosofías segundas, definían sus propios métodos y criterios al margen de la filosofía primera, se dio un conflicto entre las mismas ciencias que buscaron - y todavía buscanocupar cada cual el trono vacío de la filosofía primera, por lo que no son pocos los científicos que intentan interpretar el mundo en una clave propia de la física o de la química con las categorías propias de estas ciencias, e incluso explicar asuntos de índole metafísica acudiendo exclusivamente a criterios y conceptos de las ciencias naturales, como es el caso de los biologistas.

No es algo distinto lo que ocurre con el expresivismo o emotivismo moral al que alude MacIntyre, pues en el fondo dicha corriente de pensamiento moral pone los sentimientos y las emociones por encima del entendimiento práctico, lo cual terminaría en formas de biologismo y psicologismo que no sólo constituyen una manifiesta petición de principio - al sostener sin lograr demostrar que son las emociones las que explican los juicios morales-, sino que también contradicen innumerables casos de la Historia en que personas concretas han actuado en contra de sus emociones para obrar de acuerdo con cánones morales que consideran dignos de ser venerados. MacIntyre (2017) presenta un obstáculo inicial a esta teoría de la acción moral:

Una primera objeción, además obvia, a esta teoría emotivista sobre "lo bueno" y otras expresiones evaluativas es que entra en conflicto con algunos de nuestros usos lingüísticos habituales de "verdadero" y "hecho", como cuando afirmamos que "es un hecho que es malo gozar de la desgracia ajena", o cuando respondemos a la afirmación que alguien ha hecho sobre que el crecimiento del desempleo es malo diciendo que "lo que acabas de decir es cierto". ¿Qué dirían los emotivistas de esto? (p. 27).

Sucede esto en casos como el de San Maximiliano Maria Kolbe, clérigo franciscano de origen polaco quien ofreció su vida en Auschwitz por salvar la de un sargento del ejército polaco que había intentado escapar y fue condenado a la ejecución. Si bien el emotivista podría objetar que San Maximiliano condenaba la ejecución del sargento porque le hacía sufrir, resultaría más que absurdo afirmar que pidió a las SS que lo ejecutaran a él a cambio del militar — que tenía esposa e hijos- porque con ello expresaba un deseo de ser asesinado por inanición o por medio de la inyección letal que finalmente lo mató. Por lo menos, en honor a la verdad, el emotivista debería considerar que su planteamiento se resquebraja con los muchos casos de sacrificio de la voluntas ut natura - acto de la voluntad que sigue a juicios de tipo intelectivo, es decir, los que no suponen un proceso discursivo del cual sean su conclusión- en bien de la voluntas ut ratio — acto de la voluntad cuando la operación de la razón es comparativa-y el gran ejemplo histórico sería el de Jesucristo, quien, encontrándose en la cima del dolor y la angustia, exclamó: "Padre, si quieres aparta de mí este cáliz; pero no se haga mi voluntad, sino la tuya" (Lucas 22:42). El teólogo alemán Karl Adam (1973) explica esta diferencia para el caso puntual de la Pasión de Cristo, paradigma de sacrificio del que la muerte de San Maximiliano es una gran analogía: 
Las fuerzas de la tierra, como bestias feroces desgarraron su cuerpo, y el temor y la angustia penetraron hasta la región sensible de su alma procurando confundir y desalentar su apetito natural (voluntas ut natura).

Se desencadenaron sin freno para conturbarlo, mas no lograron penetrar hasta lo más íntimo de su ser, hasta la región donde su espíritu y su voluntad racional (voluntas ut ratio) ejerce su dominio. Y por más conturbada que se quedara de angustia y dolor, sin poder adelantar a no ser con tanteos y como en la oscuridad, esa voluntad persevera inquebrantable en su obediencia al Padre. Hay en ella una “impecabilidad”, una firmeza inconmovible como no las tuvo jamás voluntad humana alguna (p. 256).

Por otra parte, aun cuando se acepta con MacIntyre que la cultura moderna es emotivista y que dicho emotivismo está opacando y frustrando el trabajo serio de los filósofos morales que aún quedan, hay que distinguir el ser del deber - sin oponerlos- y estos del acontecer, o sea, el hecho de que el emotivismo campee a sus anchas no significa que su planteamiento central sea correcto, pues a parte de las objeciones que presenta MacIntyre y que aquí se ofrecen, podría respondérsele al emotivista, recordando primero las palabras de Nietzsche, para quien la postura emotivista quedaría reducida a una interpretación, según lo que él mismo dijo de su famosa máxima:

Contra el positivismo, que se queda en el fenómeno "sólo hay hechos", yo diría, no, precisamente no hay hechos, sólo interpretaciones. No podemos constatar ningún factum "en sí": quizás sea un absurdo querer algo así. "Todo es subjetivo", decís vosotros: pero ya eso es interpretación, el "sujeto" no es algo dado sino algo inventado y añadido, algo puesto por detrás. — ¿Es en última instancia necesario poner aún al intérprete detrás de la interpretación? Ya eso es invención, hipótesis (Nietzsche, 2008).

En el caso de la gran máxima de los emotivistas o expresivistas, habría que contestarles, no sin sorna: ¿Es eso una emoción un razonamiento? Y si es sólo una emoción ¿Por qué pretender imponerla por encima de las de otros? El emotivismo de la Moral representa el fin de la filosofía moral y de la moral misma, pues es el correlato volitivo del relativismo gnoseológico que no puede fundamentar ningún juicio moral, conduciendo así al relativismo axiológico. Si se toma en cuenta que el emotivismo es consecuencia del orgullo propio de un hombre educado bajo los dogmas derivados del principio kantiano de autonomía, pero en una velocidad que deja atrás el racionalismo y desemboca en el irracionalismo, puede concluirse con el magistral escolio del pensador colombiano Nicolás Gómez Dávila (2005): "El relativismo axiológico no es teoría de la razón, sino ideología del orgullo. Que nada prevalezca sobre nosotros" (p. 122).

Al imponerse el relativismo y el emotivismo, que dejan de lado cualquier posición que intente fundamentarse en la razón arguyendo que ésta es violenta -incluso considerando que toda afirmación explícita, lógica, secuencial y coherentemente argumentada es una imposición, una ofensa, un ultraje (Figari, 1998)—, desaparece la metafísica - muerta para muchos de los que se dedican al estudio de este asunto fundamental- y por consiguiente, las distintas ramas de la filosofía hacen su propio camino sin conexión alguna con las demás, como si la realidad a la que se aproximaran fuera totalmente distinta y como si los conocimientos adquiridos por otras ramas no aportaran absolutamente nada a sus propias indagaciones.

Así pues, se considera mayoritariamente que la filosofía política debe prescindir de la ética, convirtiéndose en una mera historia de las ideas políticas; a su vez se afirma que la ética debe dejar a un lado cualquier consideración antropológica, reduciéndose al estudio de las teorías morales, y se predica que la antropología no se sustenta en ninguna naturaleza estable e inalterable del hombre, sino que responde a prácticas y costumbres culturales, quedando como mera sociología — que por lo demás, en las facultades de Derecho está reemplazando, mediante la asignatura llamada Sociología Jurídica, a una genuina filosofía del derecho-, razón por la cual en los estudios académicos de antropología existe una lamentable ausencia de fundamentación filosófica que conduce a recelos y desprecios por parte de los antropólogos hacia los filósofos, y de estos hacia aquellos, ocurriendo lo mismo con otras disciplinas que continúan su camino sin encontrarse y, tal vez por eso, sin llegar ninguna parte, pero lo que es peor, alimentando el emotivismo y el orgullo en los estudiantes que son cada vez menos capaces de cuestionar sus propias ideas y son mucho menos tolerantes a la objeción, la crítica o la pregunta. La generación de los llamados centennials y los $\mathrm{T}$ (tecnológicos o táctiles) presenta síntomas 
de marcada debilidad y en ellos el emotivismo raya con lo patológico y ocasiona severas enfermedades psicológicas y psiquiátricas, como bien ha mostrado Seligmann (2014). El pensamiento débil con su marcado carácter anti-metafísico parece haber alcanzado su clímax:

\begin{abstract}
Así, hablar de debilidad del pensamiento, de debilidad ontológica, es hablar también de la debilidad del lenguaje. Es su consecuencia lógica. Si el irracionalismo de Nietzsche, y los vestigios de una praxis sobre la metafísica, como en el paradójico caso de Giovanni Gentile, dan a Vattimo un lugar entre los finiilustrados, esto no es difícil de verificar cuando se ve su armonía — aunque desde otra perspectivacon Karl Popper y su "pobreza para conocer". Y si hay pensiero debole, entonces hay una consecuente adhesión débil, una débil coherencia, y así en adelante. Vattimo, pues, forma parte de ese grupo de escépticos del conocimiento y de la verdad; en su caso, como ya he dicho, con sus notas particulares, con sus accidentes, pero con el mismo núcleo. Lenguaje anticoercitivo, pensamiento moral y lenguaje débil, y “corrección política", son todas manifestaciones del escepticismo y relativismo que hoy está presente en la anticultura (Figari, 1998: 22).
\end{abstract}

Si bien, para gusto de los realistas éticos duros — como quienes aquí escriben-, la particular mirada de MacIntyre en torno a los principales tópicos de la ética tiene demasiados acercamientos con corrientes como el comunitarismo, lo cierto es que el núcleo de su planteamiento es rico y desafiante, pues demuestra que los conflictos de la Modernidad no se resolverán con una ética cualquiera o con cualquier propuesta que se ponga el adjetivo de "ética", sino con aquella que tenga una raigambre metafísica cierta. Esto trasciende el ámbito de la filosofía moral y exige una consideración sobre el estado actual filosofía misma y un examen de conciencia general sobre la fidelidad del actual ejercicio filosófico académico con el espíritu en el que surgió este concepto y que inspiró al filósofo y al filosofar.

\title{
4. Aproximación metafísica y Ciencias Sociales.
}

Una de las temáticas que con más interés se ha estudiado y desarrollado en el contexto contemporáneo del panorama científico, es el de la interdisciplinariedad, entendida como la cooperación de varias ciencias o disciplinas en vistas a la comprensión de un determinado objeto de estudio. Tal preocupación por este diálogo de saberes surge como reacción a las dificultades que ha dejado una cierta comprensión de la especialización, la cual si bien es inherente a un trabajo científico riguroso y objetivo (Agazzi, 2000), al ser mal entendida o mal aplicada, puede llevar a un solipsismo de las ciencias que las aleja unas de otras e impide un conocimiento integrador de la realidad, así como a la formación de profesionales e investigadores de distintas áreas que son incapaces de trabajar sinérgicamente con colegas de otros campos del conocimiento. Se pierde así la amplitud del océano en nombre de la profundidad, pero ¿será verdaderamente profunda esa opción?

En las líneas que siguen se pretende explorar la relación entre la interdisciplinariedad contemporánea y la metafísica en la obra de Aristóteles, intentando evidenciar que finalmente, el fundamento de tal diálogo entre las Ciencias Sociales sólo puede sostenerse y justificarse a partir de una concepción metafísica del mundo - cuyo gran hito o paradigma es la teoría platónica de las ideas- que permite una visión unitaria del conocimiento, en lo que se revela el carácter sinóptico de la metafísica clásica, pues ésta no sólo permite ir ascendiendo en los grados de conocimiento desde lo más incierto y múltiple hasta lo más verdadero y uno, sino que por otro lado, ofrece la posibilidad importantísima de mostrar las relaciones entre los diversos saberes facilitando su visión conjunta:

Hemos de establecer si corresponde a una o a diferentes ciencias el estudio de los <principios $>$ llamados axiomas en las matemáticas y el estudio de la entidad. Es, desde luego, evidente que la investigación acerca de aquéllos corresponde también a la misma, es decir, a la del filósofo, ya que pertenecen a todas las cosas que son y no a algún género particular con exclusión de los demás. Y, ciertamente, todos se sirven de ellos: como que son principios de lo que es, en tanto que algo es, y cada género particular es algo que es; no obstante, se sirven de ellos hasta donde le resulta suficiente, es decir, hasta donde se extiende el género acerca del cual llevan a cabo sus demostraciones. Por consiguiente, y puesto que es obvio que tales principios pertenecen a todas las cosas en tanto que cosas que son (esto, en efecto, es lo que tienen de común), su estudio corresponde también al que se ocupa en esclarecer lo que es, en tanto que es. (Aristóteles, 1994: 19-29). 
Poner en diálogo los saberes y ubicarlos según el lugar que les corresponde en el gran sistema metafísico que es el conocimiento de la totalidad de lo real, es lo que permite conectarlos descubriendo su lenguaje común, pues finalmente, aunque cada uno tiene su objeto u objetos muy bien delimitados, las cosas a las que se refieren son las mismas, pues hacen parte de la misma realidad. En el capítulo III de ECM, Moral y Modernidad, MacIntyre identifica como tercer aspecto sobresaliente de la Moral el solipsismo y la desconexión entre las ciencias confrontándolo con un planteamiento neoaristotélico:

Para los exponentes de la Moral, igual que para quienes la ponen en práctica, "lo moral" ha de distinguirse de "lo político", "lo legal", "lo estético", "lo social" y "lo económico". Desde la visión global de la Modernidad, cada una de estas expresiones da nombre a un aspecto distinto de la actividad humana, $\mathrm{y}$, a medida que surgen las disciplinas académicas, cada uno de estos aspectos da lugar a una disciplina distinta con su propia temática particular, una que puede estudiarse en su mayor parte sin hacer mucha o ninguna referencia al resto. Desde la visión aristotélica, en cambio, cada uno de estos aspectos de la actividad humana solo puede entenderse adecuadamente si se lo pone en relación con el resto, porque de un modo $\mathrm{u}$ otro $\mathrm{y}$ en unas $\mathrm{u}$ otras circunstancias todos los aspectos tienen que ver con la consecución de los bienes correctamente priorizados, y, en consecuencia, con alcanzar el bien humano último. Aristóteles creía que la ética era un área de investigación que debía formar parte y subordinarse a la política entendida esta de un modo significativamente distinto a como hoy la entendemos - y que la propia vida política era una vida incompleta, porque la consecución del bien humano último está más allá de la política. Desde una perspectiva neoaristotélica contemporánea, la economía, la sociología y el estudio de las leyes necesitan ser entendidos dentro del marco que proporcionan las indagaciones ético-políticas, de forma que preguntemos, respecto de cada tipo de actividad económica y relación social, qué contribuye a sostener y a socavar esos tipos de estructuras institucionales, organizacionales y sociales a través de las cuales los bienes comunes e individuales se alcanzan (p. 117).

Cuando Sócrates interroga y entra en diálogo con los distintos interlocutores que aparecen en los diálogos platónicos, no lo hace desde un lenguaje especializado o técnico, sino que habla desde el lenguaje del hombre común, denotando con ello que aunque exista la especialización, inherente al conocimiento mismo, ésta no debe nunca convertirse en un obstáculo para comunicar lo conocido al no especializado, ni para conectar el conocimiento de una ciencia o disciplina particular con el de otras por medio del lenguaje común que proporciona la filosofía que, precisamente, sigue teniendo en Sócrates a su gran modelo, y a quien no puede dar la espalda sin causarse un gravísimo daño.

Por consiguiente, es el filósofo, en su genuina aproximación metafísica a la realidad, el principal responsable de contribuir a una genuina síntesis entre las Ciencias Sociales que permita aprovechar los hallazgos de cada una, ponerlos en diálogo con los resultados de la investigación en otros campos y, por medio de esta perspectiva integradora y holística, a la que bien podría llamarse sinóptica, elevar el entendimiento humano a la consideración de los primeros principios y las primeras causas, mediante la cual será posible una aproximación renovada y enriquecida de las ciencias particulares, que supere el solipsismo y hermetismo en el que hoy se encuentran. La obra de MacIntyre será siempre un muy buen ejemplo de esta metodología en que lo metafísico fundamenta lo antropológico que, a su vez, da base a los demás planteamientos que constituyen el edificio de su sistema, en lo cual se evidencia una fidelidad al paradigma aristotélico del conocimiento y al espíritu de diálogo entre los saberes e interdisciplinariedad.

A nuestro entender las ideas fundamentales pueden ser categorizadas como específicas de la investigación interdisciplinar o como las pertenecientes a una tradición de investigación; dentro de estas dos grandes categorías se hallan las mencionadas ideas propiamente dichas: el enfoque antropológico, sociológico e histórico de las acciones humanas; la historia y el lenguaje como respaldo de la filosofía; la armonía entre la ética y la política; la tradición aristotélico-tomista; la unidad de praxis y teoría; la confrontación de tradiciones y la crisis epistemológica; y una determinada epistemología.

MacIntyre elabora su pensamiento a partir de la consideración de las características fundamentales del ser humano. Por este motivo, la antropología filosófica será el punto de referencia a partir del cual se desarrollarán todas sus argumentaciones. La historia y la sociología le permiten al filósofo escocés otorgar a las acciones humanas una identidad social y temporal, con el fin de no incurrir en construcciones abstractas e inaplicables a la realidad. También MacIntyre recurre a la historia y al lenguaje como herramientas imprescindibles para la significación de los conceptos filosóficos, y a la interrelación entre la moral y la política para el estudio del bien individual y común de los seres humanos (Fernández, 2010: 145). 
Por otra parte, como ha señalado Chambers en diferentes trabajos (2012, 2013), MacIntyre sostuvo, desde Tras la virtud - y esto se mantiene en su última obra- que, para recuperar la moralidad y el ámbito normativo del mundo social habida cuenta de su irracionalidad e inconmensurabilidad, es menester unir de nuevo los hechos y los valores, es decir, la metafísica y la ética, la evaluación y la praxis, la teoría y la práctica por medio de un retorno a la filosofía aristotélica, en cuyo abandono radica la crisis de la Modernidad. Este rechazo del aristotelismo condujo a que la explicación acerca de las acciones humanas fuera vista, como desvelamiento de sus mecanismos fisiológicos, más sin tomar en cuenta la naturaleza humana.

\section{Comentarios finales.}

Más que continuar su acelerado tránsito hacia el abismo nihilista posmoderno, las ciencias y, de modo particular, las Ciencias Sociales, están en la urgente obligación de conducirse según el paradigma integrador de la metafísica propio de la filosofía perenne que las obras de Alasdair MacIntyre representan de modo más que eminente en el pensamiento contemporáneo.

El hombre moderno tiene - como le indicaba Escrutopo a su querido sobrino Orugario en las Cartas del diablo a su sobrino (Lewis, 2015) - una docena de filosofías incompatibles bailoteando juntas en su cabeza, lo cual es efecto de las ideologías que se han sucedido unas a otras de modo vertiginoso entre los siglos XVII y XXI. Los investigadores de las Ciencias Sociales en la actualidad dicen tener como punto de partida una neutralidad e imparcialidad evaluativa que, fuera de ser imposible, no se verifica en sus trabajos permeados, sobre todo, por el discurso marxista, y de modo más específico, por las teorías críticas provenientes de la Escuela de Frankfurt. Su metafísica — si así se le puede llamares nihilista y se va convirtiendo en un tribunal de inquisición académica que condena a todos los que no comparten esta perspectiva. Ante el sinsentido y el absurdo de estas propuestas que han tiranizado casi todas las facultades de Ciencias Sociales del mundo, el orden y la coherencia de la tradición aristotélico-tomista es, sin lugar a dudas, el único salvavidas real pues, además de tener una secuencia lógica irrefutable, no niega los fundamentos metafísicos y éticos realistas que están en su base, y por otro lado, no tiene por qué hacerlo, ya que una de sus virtudes destacadas es la veracidad. En este empeño de reconstrucción de los saberes, la obra de Alasdair MacIntyre será siempre un referente obligado que los vinculará con la filosofía perenne.

\section{Referencias}

Adam, K. (1973). Jesucristo. Herder. Barcelona.

Agazzi, E. (1978). Temas y problemas de filosofía de la física. Herder. Barcelona.

Agazzi, E. (2000). Filosofía de la Naturaleza. Ciencia y Cosmología. Fondo de Cultura Económica. México.

Aristóteles. (1994) Metafísica. Gredos. Madrid.

Aristóteles. (1998). Ética Nicomáquea. Ética Eudemia. Gredos. Madrid.

Bruno, G. (2018). De la causa, el principio y el uno. Tecnos. Madrid.

Buitrago, F. (2017). La facultad de teología dentro de una universidad de estudios generales. Albertus Magnus. Revista Interdisciplinar de Estudios Filosóficos y Teológicos. 8. (2): 197-212.

Cicerón. (2005). Disputaciones Tusculanas. Gredos. Madrid.

Cordero, N. L. (2009) La invención de la filosofia. Una introducción a la filosofía antigua. Biblos. Buenos Aires. 
Chambers, P. (2012). "La filosofía de Alasdair MacIntyre para el contexto latinoamericano: problemas ético-filosóficos en Freire, Fals Borda y las ciencias sociales críticas”. En Chambers, P. \& Espinal Restrepo, V. (Coords.) Conflicto armado: interpretaciones y transformaciones. (pp. 63-108). Sello Editorial Universidad de Medellín. Medellín.

Chambers, P. (2013). "Las ciencias sociales como otro escenario del conflicto colombiano: Una mirada desde la filosofía de Alasdair MacIntyre". Co-herencia 10: 223-252.

De Aquino, S T. (2001). Suma de Teología I. Parte I. Biblioteca de Autores Cristianos. Madrid.

Fernández F. (2010). Complementariedad entre la ética y la política en el pensamiento de Alasdair MacIntyre. (Tesis doctoral. Universidad de Granada). Recuperado de https://digibug.ugr.es/bitstream/handle/10481/17574/19557097.pdf? sequence=1\&isAllowed=y

Figari, L. (1998). Lenguaje, homogeneización y globalización. Vida y Espiritualidad. Lima.

Gay, B. (2004). Curso de Filosofía. RIALP. Madrid.

Gómez, J. (2005). Escolios a un texto implícito Tomo I. Villegas editores. Bogotá.

Heródoto. (1992). Historia Libros I. Clío. Gredos. Madrid.

Kant, I. (2006). Crítica de la razón pura. Taurus. México.

Lewis, C. S. (2015). Cartas del diablo a su sobrino. RIALP. Madrid.

Llano, A. (2015). Humanismo cívico. Encuentro. Madrid.

MacIntyre, A. (2012). Dios, filosofia, universidades. Historia selectiva de la tradición filosófica católica. Nuevo Inicio. Granada.

MacIntyre, A. (2017). Ética en los conflictos de la Modernidad. Sobre el deseo, el razonamiento práctico y la narrativa. RIALP. Madrid.

Nietzsche, F. (2008). Fragmentos Póstumos Volumen IV (1885-1889). Tecnos. Madrid.

Pieper, J. (1974). El descubrimiento de la realidad. RIALP. Madrid.

Platón. (1992). Diálogos II. Gorgias, Menéxeno, Eutidemo, Menón, Crátilo. Gredos. Madrid.

Plotino. (1998). Enéadas V-VI. Gredos. Madrid.

Seligmann, S. (2014). "La falta de fortaleza y los síntomas neuróticos”. Sapientia LXX, (236): 119130.

Whitehead, A. (1937). "Remarks". Philosophical Review. 3: 178-186. 